\title{
The Structure of Phage-Like Objects Associated with Non-Induced Bacteriocinogenic Bacteria
}

\author{
By D. E. BRADLEY AND C. ANN DEWAR \\ Department of Zoology, University of Edinburgh, West Mains Road, \\ Edinburgh 9, Scotland
}

(Received 11 March 1966)

\section{SUMMARY}

Phage-like objects obtained from bacteriocinogenic strains of Escherichia coli, Pseudomonas aeruginosa and Listeria monocytogenes by the differential centrifugation of culture fluids were examined in the electron microscope. Particles with small heads and contractile tails were found associated with strains of $\boldsymbol{E}$. coli. The three $\boldsymbol{P}$. aeruginosa strains all produced numerous headless contractile tails in broth cultures together with a very few phage-like objects with flexible non-contractile tails. The headless tails possessed cores which appeared both solid and hollow in the electron microscope, indicating the presence of some unidentified substance, perhaps nucleic acid. The only type of particle found associated with $L$. monocytogenes was a large bacteriophage with a complex contractile tail. The structure of these particles is described and discussed, and it is concluded that some of them are the bactericidal principles of spontaneously released bacteriocins.

\section{INTRODUCTION}

The bacteriocins are a group of highly specific antibiotics, of which only a few have been studied in detail while a great many have been isolated and classified (for recent review see Reeves, 1965). The individual bacteriocin 'species' are usually referred to by a derivation of the Linnaean specific name of the organism which produces them. For example, the bacteriocins of Escherichia coli and Listeria monocytogenes are called colicins and monocins respectively. The characteristic physiological property of bacteriocins is their ability to kill a sensitive cell, but not to multiply within it. They are perpetuated by genetic information within the host in the form of plasmids, vegetative particles released in the same way as temperate bacteriophages; they may be spontaneously produced in host cell cultures or may have to be induced.

Comparatively few attempts have been made to study the morphology of bacteriocins with the electron microscope. Kellenberger \& Kellenberger (1956) showed phage-like particles associated with a colicin-producing strain of $\boldsymbol{E}$. coli. More recently Sandoval, Reilly \& Tandler (1965) and Endo, Ayabe, Amako \& Takeya (1965) found that colicinogenic $E$. coli wT 15 produced similar particles which were identified as the bacteriolytic principle (Colicin 15). These were small-headed phagelike particles with contractile tails and were apparently identical to the virulent coliphage E 1 (Bradley, 1963). Electron microscopy has also shown that the purified pyocin produced by Pseudomonas aeruginosa strain $\mathbf{R}$ consisted of short rods 
identical to headless tails of contractile bacteriophages (Ishii, Nishi \& Egami, 1965); the rods were found both contracted and extended.

A few phage-like particles which are apparently identical to bacteriocins, but which have not been classified as such, have been isolated for several Bacillus species (Seaman, Tarmy \& Marmur, 1964; Ionesco, Ryter \& Schaeffer, 1964; Stickler, Tucker \& Kay, 1965; Bradley, 1965 $a$ ). These-so-called 'killer' particles were described as defective temperate bacteriophages lacking the ability to multiply intracellularly but able to lyse a sensitive cell. They are thus physiologically identical to bacteriocins. Those studied in greatest detail in the electron microscope were of similar basic morphology to bacteriophages with contractile tails, but had unusually small heads, only about $300 \AA$ in size. More conventional forms with contractile and non-contractile tails were also encountered.

From these observations it seems probable that a substantial number of bacteriocins are phage-like particles or phage components. The present communication describes the results of an electron microscopic examination of these particles associated with bacteriocinogenic strains of Escherichia coli, Pseudomonas aeruginosa and Listeria monocytogenes.

\section{METHODS}

Host bacteria. A number of bacteriocinogenic strains of the species mentioned above were kindly supplied by Dr Y. Hamon, Institut Pasteur, Paris, and these are listed in Table 1. In addition, indicator strains were supplied for bactericidal activity tests. These were Escherichia coli $\mathrm{k} 12$, Pseudomonas aeruginosa $\mathrm{P} 1050$, and Listeria monocytogenes 23.

Table 1. Spot tests for bactericidal activity

\begin{tabular}{|c|c|c|c|c|}
\hline Species & Strain & $\begin{array}{c}\text { Bacteriocin } \\
\text { no. }\end{array}$ & $\begin{array}{c}\text { Spot test of } \\
\text { bacteria }\end{array}$ & $\begin{array}{c}\text { Spot test of } \\
\text { extract }\end{array}$ \\
\hline Escherichia coli & CL 10 & $\mathbf{H}$ & + & + \\
\hline E. coli & к 235 & $\mathbf{K}$ & + & - \\
\hline E. coli & 167 & I & + & - \\
\hline $\begin{array}{c}\text { Pseudomonas } \\
\text { aeruginosa }\end{array}$ & кR 35 & - & \pm & - \\
\hline$P$. aeruginosa & sT-6 & - & + & - \\
\hline $\boldsymbol{P}$. aeruginosa & TTC & - & \pm & - \\
\hline Listeria monocytogenes & $1896 x$ & - & $\bar{t}$ & + \\
\hline
\end{tabular}

A + sign denotes a clear area around bacteria or a clear plaque produced by a culture extract. A \pm sign denotes a veiled surround or plaque. A - sign denotes no activity.

Preparation of bacterial culture extracts. As has already been stated, bacteriocins or temperate phages are usually present in detectable numbers in cultures of the host bacterium. Suitable extracts should therefore contain sufficient particles for electron microscopy after concentration; accordingly, two simple methods of preparation were used.

In the first, double agar layer plates (Adams, 1959) of the bacteria were prepared using Oxoid nutrient broth medium at double strength. After incubation overnight at $37^{\circ}, 2-3 \mathrm{ml}$. of neutral $0 \cdot 1 \mathrm{M}$-ammonium acetate solution was poured onto the plate, which was allowed to stand for $3-4 \mathrm{hr}$ at room temperature with occasional agitation. The extract obtained was then poured off and centrifuged at 2000-3000 $\mathrm{g}$ 
for $20 \mathrm{~min}$. to remove bacteria. The supernatant was centrifuged at $15,000 \mathrm{~g}$ for $3-4 \mathrm{hr}$ to sediment any phage-like particles present. The pellet obtained was resuspended in $0.1 \mathrm{ml}$. of neutral $0.1 \mathrm{M}$-ammonium acetate and centrifuged again at $2000-3000 \mathrm{~g}$ for $20 \mathrm{~min}$. to remove any remaining bacteria. The resulting supernatant suspension was then ready for electron microscopy.

In the second method, a $10 \mathrm{ml}$. broth culture of host bacteria was incubated for about $5 \mathrm{hr}$ in a shaker at $37^{\circ}$. Bacteria were sedimented at $2000-3000 \mathrm{~g}$ for $20 \mathrm{~min}$. In some cases the culture was shaken with chloroform before centrifugation. The supernatant was then centrifuged at $15,000 \mathrm{~g}$ for $3-4 \mathrm{hr}$ and the pellet suspended in ammonium acetate solution as above. The latter method was found most satisfactory.

Spot tests for bacteriocin activity. Both bacteria and concentrated culture extracts were tested by the spot test (Bradley, 1964) for activity against sensitive indicators. This was carried out by placing a loopful of bacteria or extract on the surface of a double agar layer plate of the indicator strain. After incubation, local clearing indicated bacteriocin activity.

Electron microscopy. Negative staining with potassium phosphotungstate (PTA) was used throughout. The suspension in ammonium acetate prepared as above was mixed with an equal volume of neutral $2 \%(w / v)$ PTA solution. A carbon-coated grid was then touched on to the surface of the mixture; all but a thin film of liquid was removed from the grid with the edge of a filter paper. When dry, the specimen was ready for electron microscopy, in this case in a Siemens Elmiskop I.

One of the micrographs was printed by rotation (Markham, Frey \& Hills, 1963) as follows. A normal print was accurately centred on a gramophone turntable and fixed with adhesive tape. The turntable was then placed under an enlarger containing the original negative, and the projected image of the object of interest was carefully mated with that on the print. The enlarger was then switched off and a piece of printing paper fixed to the turntable on top of the print already there. The enlarger was then switched on for six periods of time, each equal to one sixth of the: total exposure required for a normal print; the turntable of the gramophone was rotated by exactly one-sixth of a revolution between each exposure. On developing, a rotation print was obtained in which the information from each $60^{\circ}$ segment of the image was integrated with the rest. It was found that some contrast was usually lost by this procedure, and that it was best to use an extra hard grade of paper.

\section{RESULTS}

\section{Spot tests for bacteriocin activity}

The results of spot tests of both bacteria and the concentrated culture extracts used for electron microscopy are given in Table 1. Strains producing colicins gave most activity, with clear areas more than $1 \mathrm{~mm}$. wide with sharply defined edges round colonies. Those producing pyocins gave little activity, with a $1 \mathrm{~mm}$. surround of usually veiled appearance and a diffuse edge; the exception to this was Pseudomonas aeruginosa strain sT-6. Strains of Listeria monocytogenes producing monocins (monocinogenic) formed a narrow $(1 \mathrm{~mm}$. or less) area which was clear. It can be seen from Table 1 that only two culture extracts were active against appropriate sensitive indicators; the significance of this will be discussed below. 


\section{Electron microscopy of culture extracts}

Escherichia coli strain $C L 10$. Extracts of plate cultures contained numerous headless contracted tails. Better results were obtained from broth culture extracts, however, which contained many phage-like particles with heads. In Pl. 1, fig. 1, an example can be seen to be a conventional contractile particle similar to coliphages \$2 (Bradley \& Kay, 1960) and E1 (Bradley, 1963), a form which is common in nature. The head is $650 \AA$ in size and the tail about $1800 \AA$ long. In Pl. 1, fig. 1 , the head is filled with what is presumably deoxyribonucleic acid (DNA), and the sheath is extended. There is a thin base-plate, but no obvious striations on the sheath. Both plate and broth culture extracts contained a very small number of larger particles, one of which is shown in $\mathrm{Pl}$. 1, fig. 2. It is a contractile type with a $950 \AA$ head and $2800 \AA$ tail; the one shown has a full head and contracted sheath. Others had empty heads.

Escherichia coli strains $\mathrm{K} 235$ and $16 \%$. There were very few phage-like particles associated with these strains; only one or two could be found in each electron microscope grid square. They are illustrated in Pl. 1, figs. 3, 4, and can be seen to be basically similar to the CL10 particles. The heads are about the same size (650 $\AA$ ) but the tail from strain $\mathrm{k} 235$ is rather longer $(2000 \AA)$. That from strain 167 is, however, only $1500 \AA$ long, but it has a small collar at the top of the contracted sheath.

Pseudomonas aeruginosa strains KR 35 and $S T-6$. Strain KR 35 yielded a few phagelike particles with long non-contractile tails. One with a full head is shown in Pl. 1, fig. 5, and an empty one in Pl. 1, fig. 6. The head is about $700 \AA$ in size and exhibits a six-sided outline; the $1800 \AA$-long tail has no obvious striations. These resemble the Pseudomonas phage Pc described elsewhere (Bradley \& Kay, 1960). In addition strain KR 35 contained a small number of headless contracted tails. That shown in Pl. 1, fig. 7, is $1400 \AA$ long; it has a solid core and a contracted sheath with what appear to be fibres attached to it. An extract of strain sT-6 contained no intact phage-like particles but a few headless tails in both a contracted and extended state. In Pl. 1, fig. 8, the contracted tail (length $1400 \AA$ ) is hollow. PI. 1, fig. 9, shows an extended tail, also $1400 \AA$ long, and with marked striations of periodicityof about $37 \AA$. The tail appears to be hollow for the top $225 \AA$ of its length, but solid for the rest. Both these micrographs also show small discs or perhaps spheres about $120 \AA$ in diamteter. Those at the bottom of Pl. 1, fig. 9, suggest a hexagonal outline.

Pseudomonas aeruginosa strain TTC. Like KR 35 and ST-6 this strain had headless tails associated with it, but in much larger numbers. This allowed a rather more detailed study. A group of particles is shown in Pl. 2, fig. 10. It can be seen that they are identical to those already described. Their average length is also $1400 \AA$. They seem to be solid except for the top $200 \AA$; the two contracted tails in Pl. 2, fig. 10, are also solid. There is an isolated core with a suggestion of periodicity on it at the bottom centre of the micrograph; this is empty and is readily distinguished from the full or solid cores of the contracted tails. More detail is seen in Pl. 3, fig. 11 : striations with a periodicity of about $37 \AA$ and the hollow portion of the core, particularly in the bottom right particle. In Pl. 3, fig. 12, the difference between empty and full cores is shown more clearly. The top particle has a full one, and the other two empty ones; this is a particularly important observation which will be discussed below 
In a very few cases (Pl. 3, fig. 13) the helical nature of the sheath was visible. It is a coarse helix similar to that found on T-even coliphages (Bradley, 1963). In some cases the core had slipped out of the contracted sheath leaving a short tube (Pl. 3, fig. 14); two are lying end-to-end in this micrograph. The hole of this tube is $90 \AA$ in diameter, but the cores themselves are only $60 \AA$ wide. As suggested from Pl. 3, fig. 12, there is a slight gap between the core and the tube wall of the extended sheath. The diameter of the extended sheath is $180 \AA$ and that of the contracted sheath, $225 \AA$.

In addition to headless tails, numerous long rod-shaped objects were found (Pl. 3, fig. 15). At first these might be thought to bear no relationship to the particles just described, but their diameter is $225 \AA$, like the contracted sheaths, and they resemble the polysheath of T-even coliphages (Poglazov \& Tickhonenko, 1963; Kellenberger \& Boy de la Tour, 1964).

Listeria monocytogenes strain $1896 \times$. An extract of a broth culture of this strain provided a rich suspension of phage-like particles (Pl. 4, fig. 16). As with Pseudomonas aeruginosa these were largely headless tails. However, a few similar tails attached to heads (Pl. 5, figs. 17, 18) were also found and there were numerous tailless heads (Pl. 5, fig. 19) in the preparation. All the heads, whether attached or detached, were empty; they had an average diameter of $1100 \AA$. The total tail length of $2400 \AA$ can be seen in Pl. 4, fig. 16, to consist of about $1600 \AA$ of sheath with $800 \AA$ of core projecting from the end. The sheath diameter is $200 \AA$ and that of the core about $75 \AA$. In Pl. 4, fig. 16, there is also a smaller head ( $600 \AA)$ with a longer core $(2700 \AA$ ) attached. The sheaths in Pl. 4, fig. 16, have a very fine capsomere structure whose organization is not apparent, though four parallel axial lines are very obvious. The arrangement of the tail tip is clearer in Pl. 5, figs. 17, 18. There is a distinct base-plate with two prongs at its edge (these are shown as fine fibres in Pl. 5, fig. 21) and a wedge-shaped structure below the base-plate. The cores in the first two particles (Pl. 5, figs. 17, 18) are solid, but in the headless ones they are hollow. The appearance of the sheath is also different on particles with heads: neither the fine subunits nor the longitudinal lines can be seen, though the negative staining and preservation was equally good.

In Pl. 5, fig. 20, the base-plate with its fibres is partially detached from a coreless sheath. This preparation also contained some hexagonal plates (Pl. 5, fig. 22) which can be correlated with the base-plate in Pl. 5, fig. 20. They had obviously become detached from the sheaths. The base-plate in Pl. 5, fig. 22, is clearly of sixfold rotational symmetry and may have some morphological subunits on its rim. The use of the rotational printing procedure (Markham et al. 1963) clarifies the whole structure; $\mathrm{Pl}$. 5, fig. 23, has been rotated by $120^{\circ}$ between each exposure and Pl. 5, fig. 24, by $60^{\circ}$, i.e. three and six exposures per revolution respectively. There is a progressive improvement in definition in each case clearly showing the shape of the fibres, and also revealing the presence of six subunits slightly to one side of the centre of each edge of the hexagon. Since these are more electron-transparent than the rest of the plate they must consist of a greater vertical thickness of protein.

In Pl. 6, figs. 25, 26, isolated cores are shown in the form of the usual hollow tubes. That in Pl. 6, fig. 25, appears to be pulled out from the sheath; beside it there are five small star-shaped objects. Their origin is shown in Pl. 7, fig. 28, where the sheaths have been partly degraded into individual capsomeres. These minute 
objects are hexagonal plates with a subnunit at each apex, giving them a star-like appearance; they measure about $100 \AA$ across.

A tail which has lost its base-plate is shown in $\mathrm{Pl}$. 6, fig. 27; its significance will be discussed below.

\section{DISCUSSION}

Phage-like particles from Escherichia coli. All three strains of $\boldsymbol{E}$. coli produced highly active colicins (see Table 1 ) but only one of the extracts prepared for electron microscopy possessed any killing ability. This strain (CL10) produced an abundance of phage-like particles, whereas the other two contained barely detectable numbers. Bearing in mind the low centrifugation speed used to sediment the particles it would seem that the CL10 particles represent colicin $\mathbf{H}$ but that those of the other two strains do not represent the bactericidal principle. This is of importance since Sandoval, et al. (1965) showed particles associated with $E$. coli wr 15, similar to those of CL10, which were almost certainly the lytic principle. One deduces from this that some colicins are defective bacteriophages, as suggested by Sandoval et al. (1965) for colicin 15, and some are much smaller, not being sedimented by the $15,000 \mathrm{~g}$ used in the present investigation. As Reeves (1965) pointed out, colicin $\mathrm{CA} 42-\mathrm{E}_{2}$ has a sedimentation coefficient of only $3 \cdot 6 \mathrm{~s}$ meaning that it will be quite different in form and function from colicins 15 and $\mathrm{H}$. The suggestion of Ivanovics (1962) and Fredericq (1963) that colicins are the products of defective lysogeny appears, therefore, to be partly confirmed. It does seem, however, that there may be two completely different types within this group of bacteriocins.

Although there is a basic similarity between the particles of colicin 15 illustrated by Sandoval et al. (1965) and those of colicin $\mathrm{H}$ shown here, their preparation of colicin 15 contained many empty tail-less heads as well as a substantial number of intact phage-like particles. Since the function of the particles in both cases is now defined, they may be considered physiologically similar to the so-called 'killers' of Bacillus subtilis mentioned above (see Introduction).

It is interesting to compare the size of the CL10 particle with that of coliphage E 1 (Bradley, 1963) which is morphologically similar. The heads are the same size $(650 \AA)$ but the tail of colicin CL 10 is $1800 \AA$ long compared with $1150 \AA$ for that of the phage.

Particles from Pseudomonas aeruginosa. The headless tails found associated with pyocinogenic strains of $\boldsymbol{P}$. aeruginosa all looked the same and were identical to the purified pyocin described by Ishii et al. (1965). As can be seen from Table 1, the spot tests were not conclusive, but because of the similarity to a properly purified pyocin, it is certain that these headless tails represent the lytic principle.

The pyocins have been well illustrated in order to permit a detailed comparison with the one described by Ishii et al. (1965). There is no necessity to go into details since it is abundantly clear that the structure of all four pyocins is identical. The only possible difference is in the length of the particles; those described here are $1400 \AA$ long, and those of Ishii et al. (1965) were $1200 \AA$ long. This difference is not considered significant. One or two points, however, have been omitted by these authors.

The most important and significant is the presence of both solid and hollow cores in contracted tails; this indicates unequivocally that something is present in the 
tube. The conclusion is supported by the observation that the top $200 \AA$ of extended tails is empty; the rest is presumably filled with some undefined substance. A somewhat analogous observation was made on the virulent pseudomonas phage sLo by Bradley $(1965 b)$; here a single empty contractile sheath in the extended state with a $20 \AA$ hole down the centre was found. The obvious and most likely deduction is that the material in the core is a short length of nucleic acid. Also supporting this is the fact that the nucleic acid strand of tailed bacteriophages extends from the head to the tail tip (see Bradley, 1965b). Since all known phages with contractile tails have deoxyribonucleic acid (DNA) as their genetic material, it is reasonable to suppose that the strand within these headless tails is of the same kind. Since the core is capable of being emptied and the tail is of a contractile nature, its contents are doubtless injected into the bacterium when the pyocin adsorbs to the cell surface. This short length of DNA could then misdirect the bacterial metabolism and so cause the death of the cell. It is not contended that this mode of action is anything more than a theory suggested by the presence of a structure within the tail tube. However, such a hypothesis could be confirmed by nucleic acid estimations and perhaps by suitable radioactive tracer experiments.

The nature of the minute disc-like objects in Pl. 1, figs. 8, 9, is not known. These are rather larger than those found by Ishii, et al. (1965), which seemed to be segments of cores. With a diameter of $120 \AA$ they are also too small to be segments of the extended sheath. The non-contractile phage-like particles found with KR 35 are probably temperate bacteriophages.

Phage-like particles from Listeria monocytogenes. No monocins have hitherto been examined in the electron microscope. In view of the biological activity of the electron microscope preparation, it seems that the particles observed here are the bactericidal principle. While basically of a contractile nature, no particles with obviously extended sheaths could be found. However, the sheaths of the particles in Pl. 5, figs. 17, 18, differ in capsomere structure from the others shown, though the sheath length is the same. The cores are solid, whereas the headless tails have empty ones, suggesting that the former are viable and the latter are not. In this case the head would be naturally empty and would play no part in the killing process. Such a particle could represent an intermediate stage between the colicins and the bacillus 'killers' with their full heads, and the pyocins with their headless tails.

Structurally the particles are of unusual interest mainly because it is possible to resolve the shape of the individual tail capsomeres. Two forms have been tentatively observed for those of conventional phages; short tubes and 'globular' subunits. There is no reason why the star-shaped objects should not represent short tubes seen end-on. Unfortunately there is insufficient information in the electron micrographs to suggest a model for their arrangement, let alone any change in arrangement which may attend sheath contraction. Indeed, there is no evidence to suggest that contraction occurs in the conventional manner; from what one can see, there is merely a change in capsomere packing without a shortening of the sheath. If a morphologically similar virulent bacteriophage for $L$. monocytogenes were found, this point could probably be cleared up; those known are non-contractile (Sword \& Pickett, 1961).

The tail without a base-plate shown in Pl. 6, fig. 27, is included because it bears a remarkable resemblance to the rhapidosomes or rod-shaped bodies found by 
Correll \& Lewin (1964) associated with the gliding organism Saprospira grandis. The sheath length of the latter is $1200 \AA$ and that of the monocin is $1500 \AA$. The total length of each is about the same at $2700 \AA$. The inference is that the $S$. grandis rhapidosome is a particle arising from a degenerate contractile bacteriophage.

The nature of bacteriocins. While only a few bacteriocins have so far been examined in the electron microscope, it is clear that a knowledge of their structure is valuable in elucidating their true nature. From the results obtained above and those cited in the literature, it can be said of the colicins that two kinds exist: on the one hand there are phage-like particles, and on the other smaller as yet unidentified molecules which presumably act in a different way. With the pyocins the position is different. All four examples so far studied are identical and constitute what is essentially a unique type of bacteriolytic particle. Whether or not all pyocins are the same will only be discovered after an extensive survey. The monocin examined is again different and further study is also required to see whether it is typical of the monocins as a group. Some bacteriocins which have only been mentioned here are those specific to species of the genus Bacillus; these are the Bacillus 'killers'. A number of bacteriocins specific to $\boldsymbol{B}$. megaterium (megacins) and $\boldsymbol{B}$. cereus (cerecins) also exist (see Reeves, 1965) and it is obviously important to see whether or not they resemble bacteriophages. Above all it is clear that a wide range of morphological and physiological bacteriolytic particles exist in the bacteriocins, and both the general conception and classification of the group will clearly have to be revised in the light of future work.

The authors are particularly grateful to Dr Y. Hamon, Institut Pasteur, Paris, for kindly providing the bacteria used.

\section{REFERENCES}

Adams, M. H. (1959). Bacteriophages. New York and London: Interscience Publishers.

Bradley, D. E. (1963). The structure of coliphages. J. gen. Microbiol. 31, 435.

BradLey, D. E. (1964). The structure of some bacteriophages associated with male strains of Escherichia coli. J. gen. Microbiol. 35, 471 .

Bradley, D. E. $(1965 a)$. The isolation and morphology of some new bacteriophages specific for Bacillus and Acetobacter species. J. gen. Microbiol. 41, 233.

Bradley, D. E. (1965b). The morphology and physiology of bacteriophages as revealed by the electron microscope. J. R. micr. Soc. 84, 257.

Bradley, D. E. \& KaY, D. (1960). The fine structure of bacteriophages. J. gen. Microbiol. 23, 553.

ConRela, D. L. \& Lewin, R. A. (1964). Rod-shaped ribonucleoprotein particles from Saprospira. Canad. J. Microbiol, 10, 63.

Endo, H., Ayabe, K., Amako, K. \& Takeya, K. (1965). Inducible phage of Escherichia coli 15. Virology 25, 469.

FredericQ, P. (1963). On the nature of colicinogenic factors: a review. J. theoret. Biol. 4, 159.

Ionesco, H., Ryter, A. \& Schaeffer, P. (1964). Sur un bactériophage heberge par la souche Marburg de Bacillus subtilis. Ann. Inst. Pasteur 107, 764.

Ishit, S., Nishi, Y. \& Egami, F. (1965). The fine structure of a pyocin. J. mol. Biol. 13, 428.

Ivanovics, G. (1962). Bacteriocins and bacteriocin-like substances. Bact. Rev. 28, 108. 
Kellenberger, E. \& Boy de la Tour, E. (1964). On the fine structure of normal and 'polymerised' tail sheath of phage 'T4. J. Ultrastructure Res. 11, 545.

Kellenberger, G. \& Kellenberger, E. (1956). Étude de souches colicinogènes au microscope electronique. Schweiz. Z. Path. Bakt. 19, 582.

Markham, R., Frey, S. \& Hills, G. J. (1963). Methods for the enhancement of image detail and accentuation of structure in electron microscopy. Virology 20, 88.

Poglazov, B. F. \& Tickhonenko, A. S. (1963). A study of T 2 phage contractile protein properties. (In Russian). Biokhimiya 28, 888.

Reeves, P. (1965). The bacteriocins. Bact. Rev. 29, 24.

Sandoval, H. K., Reilly, C. H. \& Tandler, B. (1965). Colicin 15: possibly a defective bacteriophage. Nature, Lond. 205, 522.

Seaman, E., Tarmy, E. \& Marmur, J. (1964). Inducible phages of Bacillus subtilis. Biochemistry 3, 607.

Stickler, D. J., Tucker, R. G. \& Kay, D. (1965). Bacteriophage-like particles released from Bacillus subtilis after induction with hydrogen peroxide. Virology 26, 142.

Swond, C. P. \& Picketт, M. J. (1961). The isolation and characteristics of bacteriophages for Listeria monocytogenes. J. gen. Microbiol. 25, 241.

\section{EXPLANATION OF PLATES}

\section{Plate 1}

Fig. 1. Small particle from Escherichia coli cL $10 . \times 180,000$.

Fig. 2. Large particle from E. coli cL 10. $\times 180,000$.

Fig. 3. Particle from $E$. coli $\mathrm{k} 235 . \times 180,000$.

Fig. 4. Particle from $E$. coli $167 . \times 300,000$.

Figs. 5, 6. Full and empty phage-like particles from Pseudomonas aeruginosa KR $35 . \times 180,000$.

Fig. 7. Contracted headless tail from P. aeruginosa $\mathrm{KR} 35 . \times 300,000$.

Figs. 8, 9. Headless tails from $P$. aeruginosa ST-6. $\times 300,000$.

\section{Plate 2}

Fig. 10. Particles from Pseudomonas aeruginosa TTC showing contracted and extended sheaths and

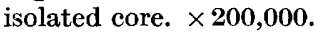

\section{Plate 3}

Fig. 11. Particles from Pseudomonas aeruginosa TTC extended sheaths showing striations and

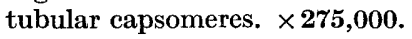

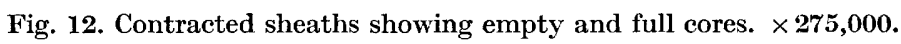

Fig. 13. Extended sheath showing coarse helix. $\times \mathbf{2 7 5 , 0 0 0}$.

Fig. 14. Isolated contracted sheaths. $\times \mathbf{2 7 5 , 0 0 0}$.

Fig. 15. Rod-shaped objects. $\times 165,000$.

Plate 4

Fig. 16. Particles from Listeria monocytogenes. $\times 200,000$.

Plate 5

Particles from Listeria monocytogenes

Figs. 17 , 18. Particles with heads. $\times 280,000$.

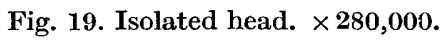

Fig. 20. Base-plate being detached from isolated sheath. $\times 280,000$.

Fig. 21. Particle showing base-plate fibres. $\times 280,000$.

Fig. 22. Base-plate. $\times 415,000$.

Fig. 23. The same, printed by rotation at three exposures per revolution.

Fig. 24. The same, printed by rotation at six exposures per revolution. 


\section{Plate 6}

Particles from Listeria monocytogenes. $\times \mathbf{2 0 0 , 0 0 0}$.

Fig. 25. Core with star-shaped capsomeres.

Fig. 26. Isolated cores.

Fig. 27. Sheath and core without base-plate.

\section{Plate 7}

Fig. 28. Sheath capsomeres from Listeria monocytogenes particles. $\times 333,000$. 

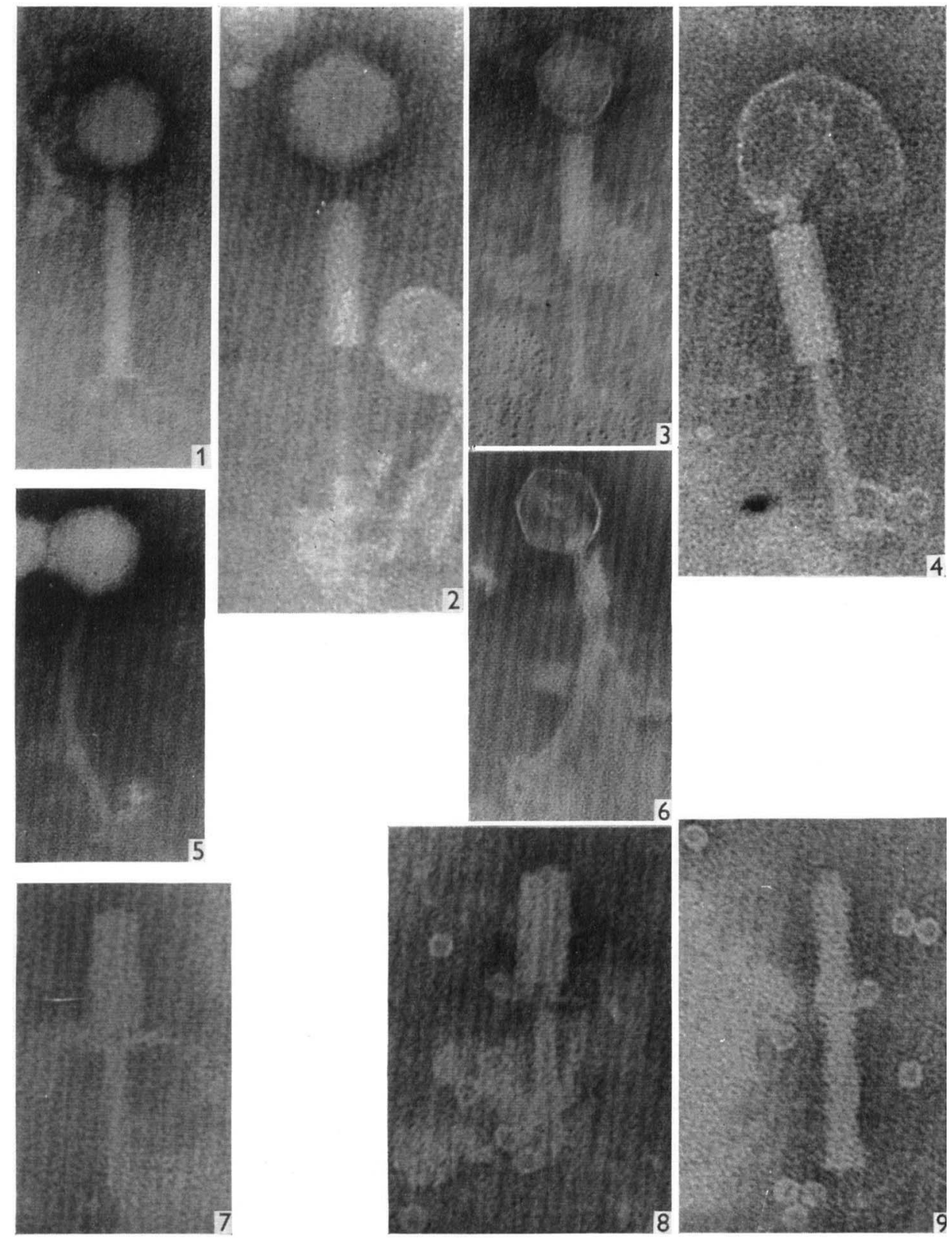


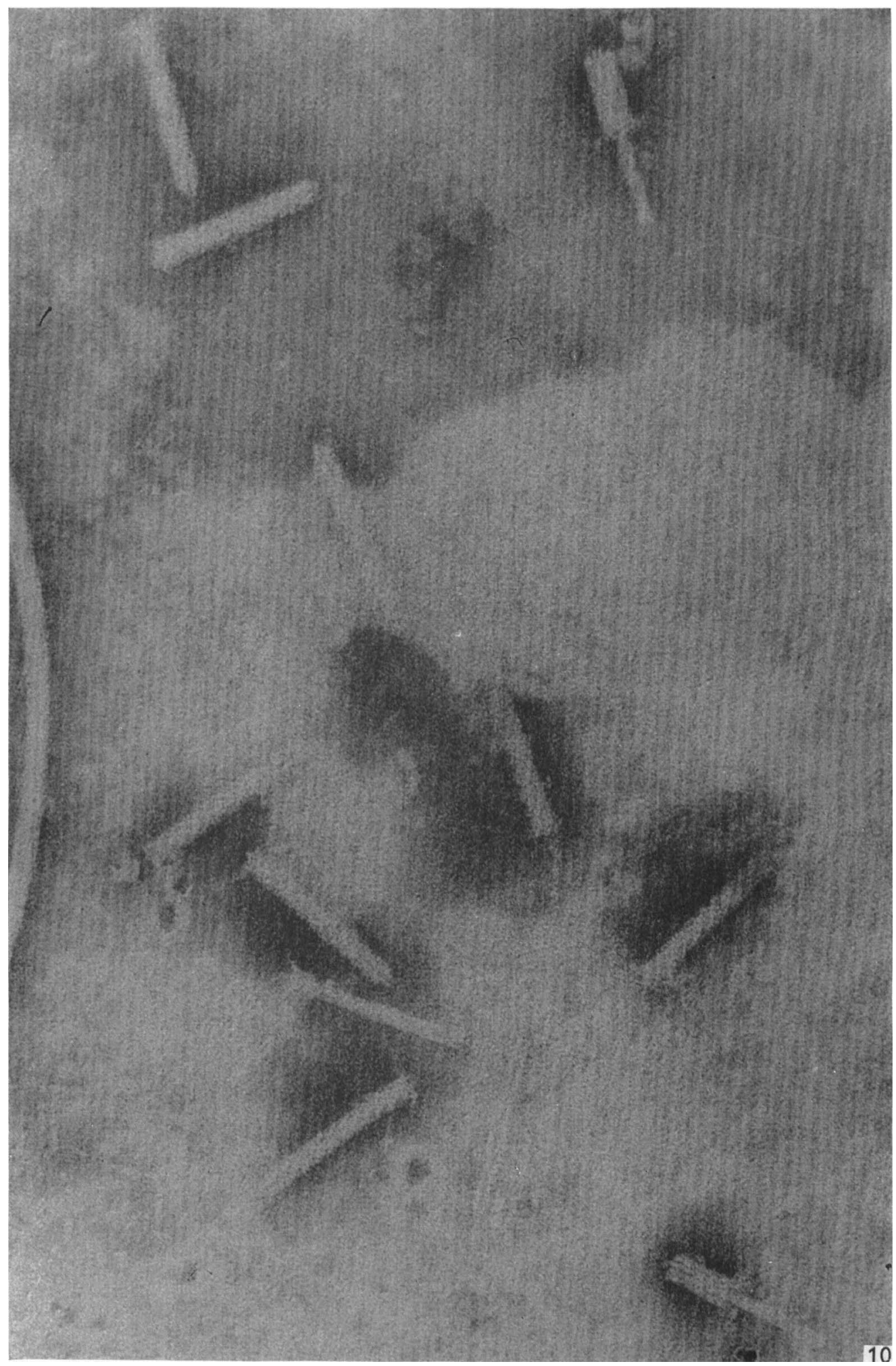

I). E. BRADLFY AND C. A. IOWWAR 

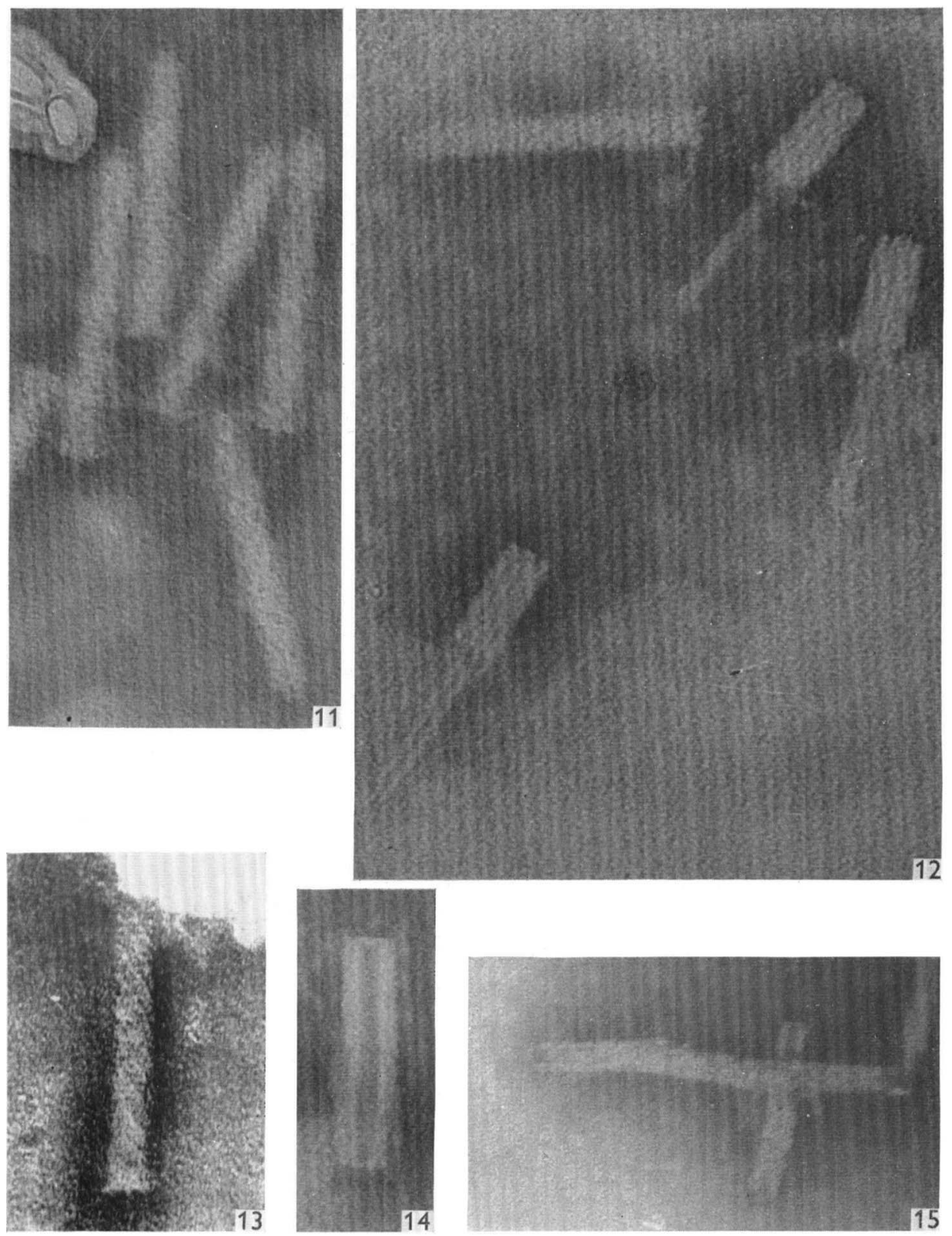

1). HA. BRADILY ANU (. A. I)IWAR 


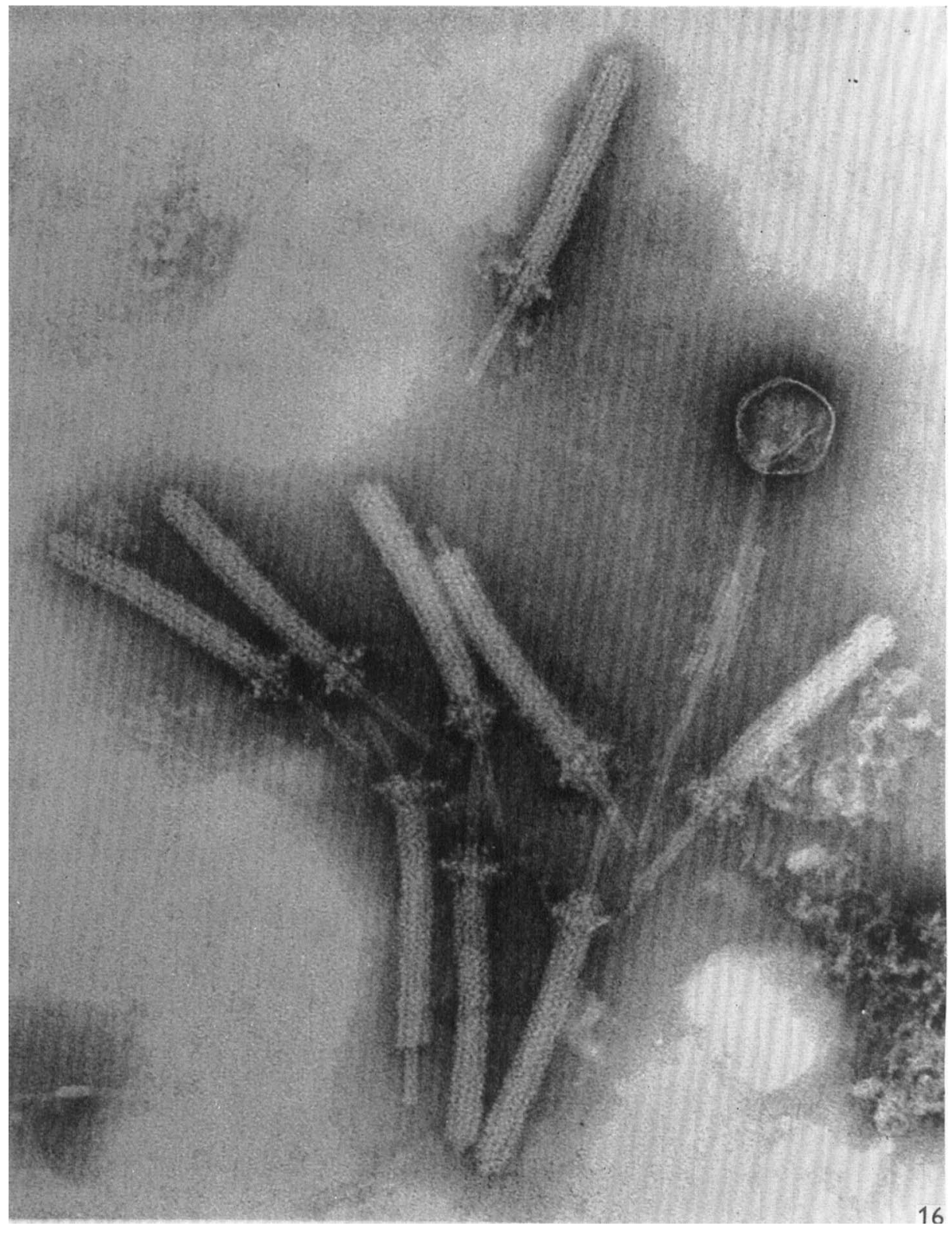

1). E. BRADLEY AN1 C. A. DEWAR 

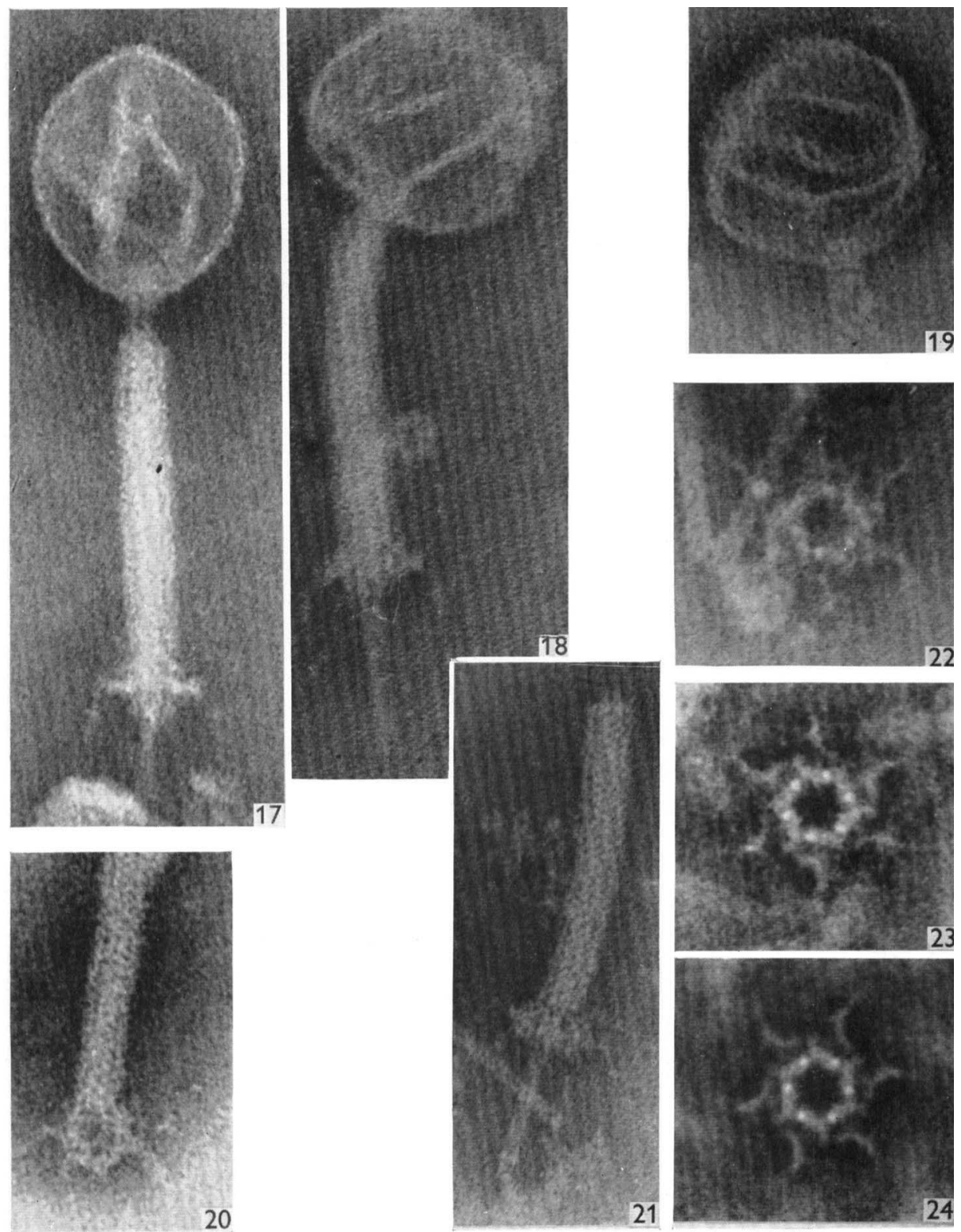

D. F. BRADLLY AND C. A. DEWAR 

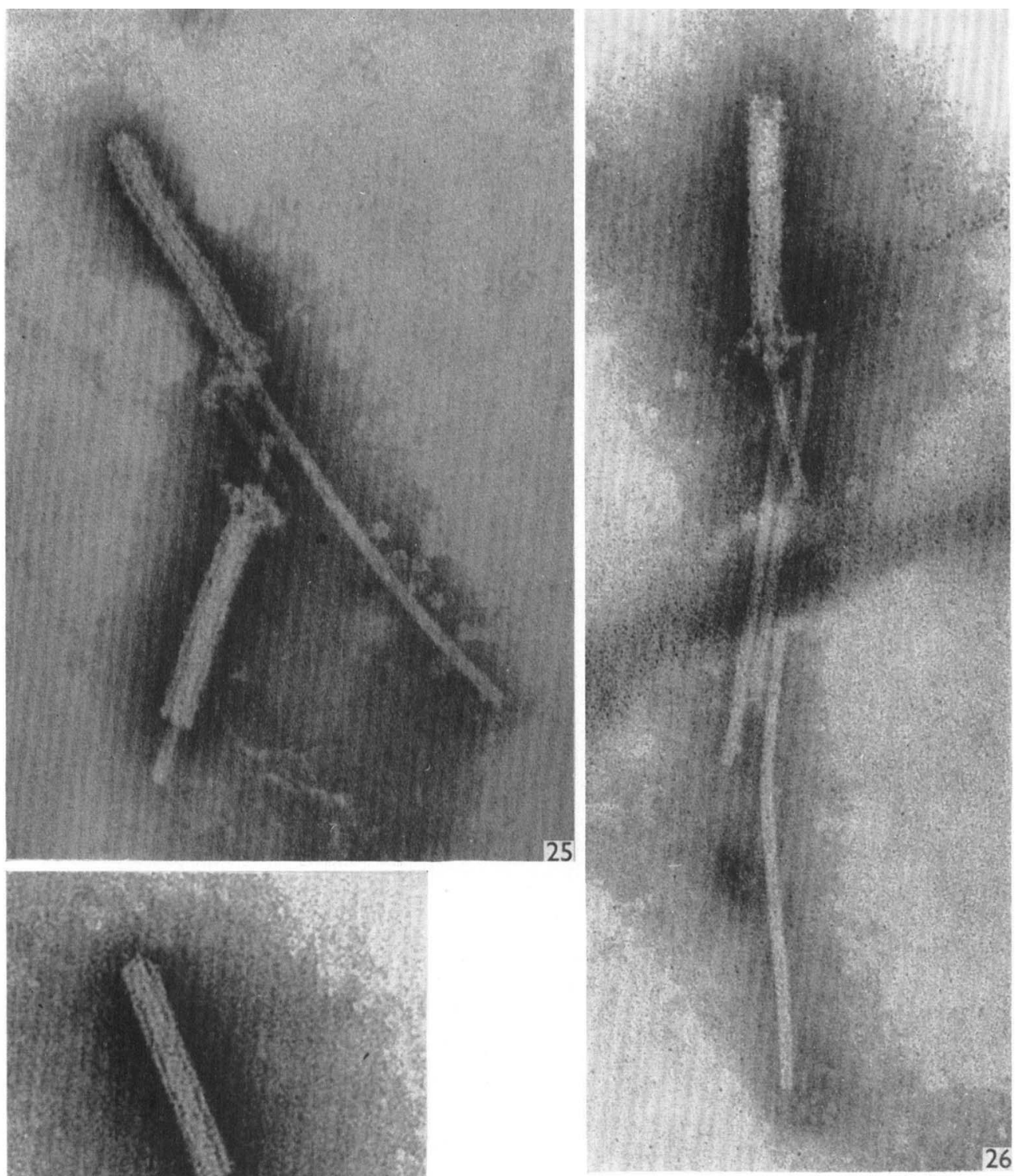

D. F. BRAIDIAY ANI $($. A. D)HWATR 


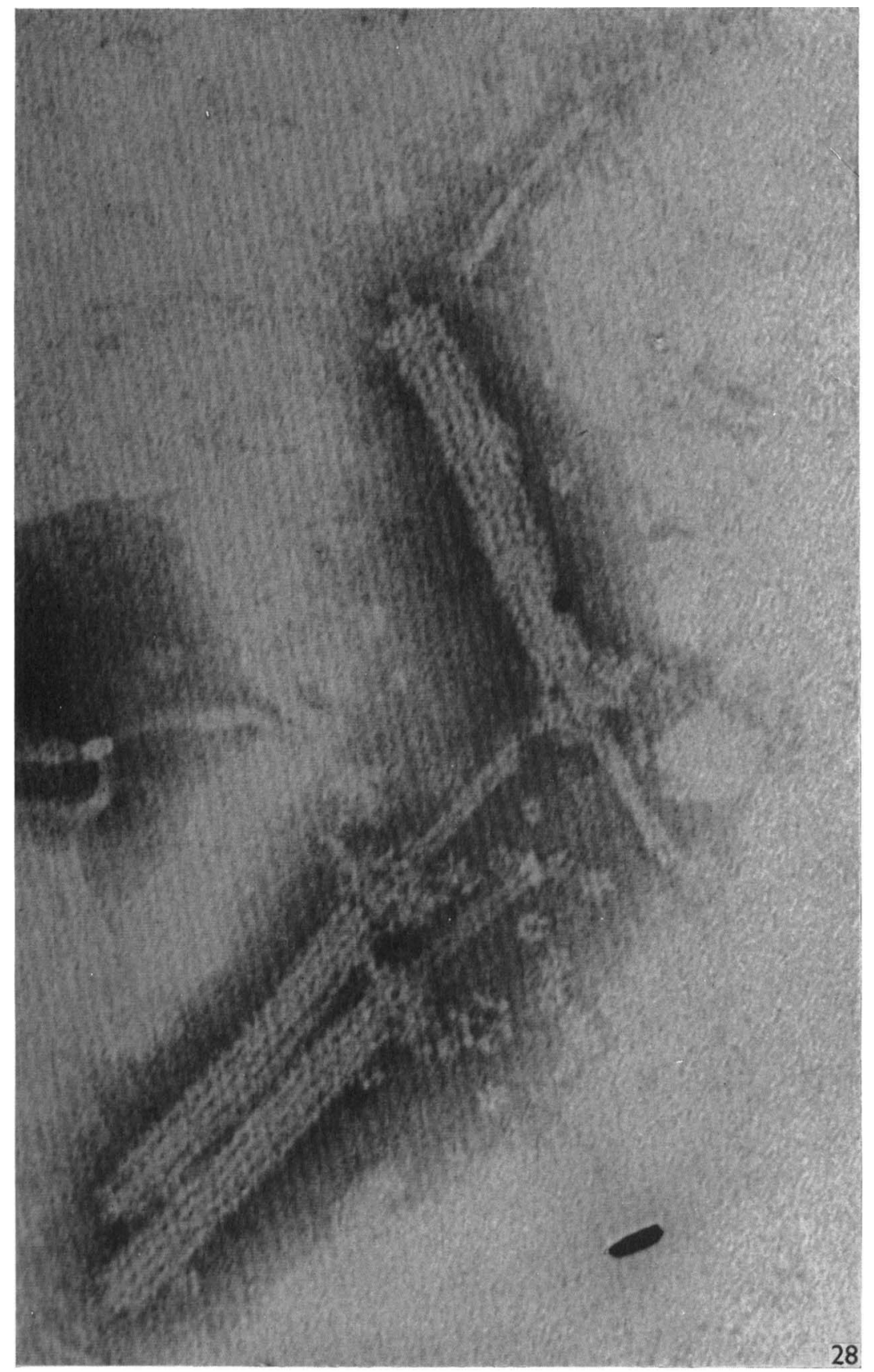

I). L. BRADLEY AND ('. A. I)IWWAR 